\title{
Changes in sovereign debt dynamics in Central and Eastern Europe
}

\author{
Juan Carlos Cuestas \\ Department of Economics \\ Jaume I University
}

And

Department of Economics and Finance

Tallinn University of Technology

And

\author{
Research Unit \\ Eesti Pank
}

The author acknowledges the financial support from the ECO2017-85503-R and ECO2017-83255-C3-3-P projects from 'Agencia Estatal de Investigación' (AEI) Spain and 'Fondo Europeo de Desarrollo Regional' (FEDER). Comments from two anonymous referees are gratefully acknowledged. The views expressed are those of the author and do not necessarily represent the official views of Eesti Pank, the European Central Bank or the Eurosystem.

email: cuestasjuancarlos@gmail.com 


\title{
Changes in sovereign debt dynamics in Central and Eastern Europe
}

\begin{abstract}
The aim of this paper is to shed some light on the degree of sustainability of fiscal debt for a group of Central and Eastern European countries. We apply a battery of time series econometrics methods to show how the financial crisis has affected the debt-to-GDP ratio and how the ratio has behaved recently. The results give us important insights into how governments in Central and Eastern Europe have reacted to the accumulation of debt. We distinguish between two groups of countries; one group where the sovereign debt stock stabilised after the crisis, and another where debt has been accumulated more quickly in recent years. The results provide important policy lessons for the authorities responsible.
\end{abstract}

Key words: debt, Central and Eastern Europe, structural breaks, European integration.

JEL code: $\quad$ C22, F15. 


\section{Introduction}

The financial crisis that hit the global economy in 2008 after the collapse of Lehman Brothers in the United States had a significant negative impact on the public finances of most developed and developing economies. Since the beginning of the crisis, many European economies have run what are known as austerity fiscal policies with the aim of reducing the high levels of sovereign debt that were generated as a consequence of the drop in economic activity. However, it is not yet clear whether these policies have helped in reducing the high levels of debt. Cuestas et al. (2014) find that in Spain for instance, where austerity measures have been quite prominent, the degree of persistence of debt increased after 2008. This may be explained by the high level of unemployment that this country has chronically suffered from. In addition, governments which lose their credibility face inherent fragility in a monetary union (De Grauwe, 2012, and Gros, 2012). This is because it is impossible to use monetary expansion to finance a deficit within a monetary union, and so the risk of default is high.

This paper focuses on analysing debt sustainability and changes in the degree of persistence of the public debt stock for a group of Central and Eastern European Countries (CEECs). The analysis seeks to shed some light on the current state of the public finances of these countries. This is of particular importance as some of these countries are still yet to fulfil the Maastricht criteria, while others are already members of the euro area. Assessing the health of the levels, evolution and dynamics of the sovereign debt stock in these countries is vital for the euro area to function well. We closely follow Cuestas and Staehr (2013), who contribute to the literature by analysing the order of integration of the fiscal budget balance for a group of CEECs. In this paper however, we aim not simply to test for unit roots, but to look at how the 
past debt stock contributes to the present fiscal deficit with interest, and how the relationship between the two variables changes over time.

Analysis of debt sustainability has gathered momentum since 2008, and works analysing different measures of debt sustainability have increased in number (see Cuestas and Staehr, 2013, and the references therein). However, there has been increasing recent interest in assessing how the sustainability of debt has changed over time, and analysis of sustainability using nonlinear models has become popular in the literature in consequence. Cuestas et al. (2014) analyse the degree of persistence of shocks to the public debt stock, and structural breaks for the EU-15 for instance. It is found in general that the year 2008 was a turning point for the degree of persistence of debt and for its sustainability. However, not all the EU-15 were equally successful at reducing debt and the actions taken by the authorities were not universally effective, as Cuestas et al. found that the degree of persistence of shocks after the end of 2007 increased for Austria, Italy and Spain. Motivated by this empirical research we analyse how the persistence of shocks to the public debt ratio over GDP may have changed over time, paying particular attention to the eruption of the global financial crisis.

A number papers have recently analysed the degree of sustainability of debt by applying univariate time series econometrics and, more precisely, by analysing the order of integration of the debt-to-GDP ratio or the deficit as a percentage of GDP as a sufficient condition for debt sustainability. According to a seminal contribution by Bohn (2007) however, the transversality condition of the intertemporal budget constraint can be satisfied for any arbitrary order of integration of the debt stock ratio over GDP, as long as the discount rate is sufficiently large (see next section). Hence the stationarity of the debt stock ratio is not a necessary condition for the transversality condition to hold. As already mentioned, there are a number of contributions that assess the order of integration of the debt to GDP ratio. Within the literature on unit root tests 
incorporating nonlinear data generation processes for instance, we find Legrenzi and Millas (2012), who apply this methodology to analyse the debt sustainability of the GIIPS countries (Greece, Italy, Ireland, Portugal and Spain), and Chortareas et al. (2008) who apply it to Latin America and the Caribbean. For the group of CEECs, Cuestas and Staehr (2013) analyse the sustainability of the fiscal balance incorporating structural breaks in the deterministic components, finding that once breaks are taken into account, there is more evidence favouring the stationarity of the fiscal balance. Taking a similar line of research, but for the external debt position, Cuestas (2013) analyses the order of integration of the external deficit for CEECs by applying unit root tests and nonlinearities, and fractional integration techniques, providing evidence of slow mean reversion after a shock (see also Cunado et al. 2004, 2010, and Holmes et al. 2011). This shows that techniques to test for the order of integration have been used frequently within the literature to analyse the sustainability of debt empirically. Other contributions for CEECs using methods other than univariate tests are Bökemeier and Stoian (2018) and the references therein. However, the results from this literature are far from conclusive as they are highly dependent on the method used. Focusing on the most recent case, Bökemeier and Stoian (2018) show that only Latvia and Romania would not be able to stabilise their debt by 2018. Krajewski, Mackiewicz, and Szymańska (2016) also find that there are no sustainability issues for the CEECs. In this article we are interested in analysing how the way that countries accumulate public debt may have changed, in particular before and after the global financial crisis ignited. We then combine tests for the order of integration of the variables with structural breaks. Our results are less optimistic than those of Krajewski, Mackiewicz, and Szymańska (2016) and Bökemeier and Stoian (2018), since a greater number of our target countries seem to have had debt sustainability issues since the crisis. 
The remainder of the paper is organised as follows. The next section summarises the econometric methods applied in this empirical analysis, section 3 presents the empirical evidence and results, and the last section concludes.

\section{Methodology}

Bohn (2007) established that debt sustainability analysis based on unit root testing over the debtto-GDP ratio lost its economic significance since sustainability, in the sense of the transversality condition of the intertemporal budget constraint being satisfied, would be fulfilled for any arbitrary order of integration of the debt stock. That is, if we define the intertemporal budget constraint as

$$
B_{t}=\sum_{i=0}^{\infty} \theta^{i} E_{t}\left(T_{t+i}-G_{t+i}\right)
$$

where $T_{t}-G_{t}$ is the fiscal budget balance at moment $t$ and $\theta$ is the discount factor, the intertemporal budget constraint would be satisfied if the transversality condition, defined as

$$
\lim _{n \rightarrow \infty} \theta^{n} E_{t}\left(B_{t+1}\right)=0
$$

holds. Given that $0<\theta<1$, the transversality condition in (2) holds for any arbitrary order of integration of $B_{t}$ (see proposition 1, p. 1840, in Bohn, 2007, for mathematical details and proof). Intuitively, the effect of discounting future fiscal deficits will dominate the stochastic trend in $T_{t}-G_{t}$, so according to Bohn (2007) proposition 3, the sustainability analysis should be based on comparison of the autoregressive parameter of the debt stock with the interest rate of debt, meaning 


$$
B_{t}=\beta B_{t-1}+\varepsilon_{t} .
$$

Note that this equation links directly to the analysis of unit roots. This means that analysing whether the debt stock has a unit root or is a stationary process provides us with some light into the way governments accumulate debt.

Instead of exclusively analysing the order of integration of the debt stock over GDP however, we look here at how the autoregressive parameter of the reaction function defined by Bohn (2007) in equation (8) on page 1844 has changed over time. We do so firstly by testing for changes in the order of integration of the fiscal debt over GDP from I(1) to I(0) and the other way, with dates endogenously determined using the Leybourne et al (2007) test; secondly by testing for unit roots incorporating structural changes in the deterministic components using the Lee and Strazicich (2003) test; and thirdly by estimating a broken equation for the reaction function, applying the Bai and Perron (2003) procedure. We are interested in testing the null $H_{0}: \beta_{t}=\beta$ vs. $H_{1}: \beta_{t}=F(t)$, where $F(t)$ is a function of time.

Leybourne et al. (2007) propose a method which allows us to find changes in the order of integration of variables with endogenously determined dates. First the authors propose a generalised least square (GLS) method to detrend the series, and then they use a Dickey-Fuller type of equation to test for unit roots:

$$
\Delta B_{t-1}^{d}=\hat{\rho} B_{t-1}^{d}+\hat{\varepsilon}_{t}
$$

where $B_{t}^{d}$ is the detrended series. The test statistic is: 


$$
M=\inf _{\lambda \in(0,1)} \inf _{\tau \in(\lambda, 1)} \operatorname{DF}_{G}(\lambda, \tau)
$$

with $\lambda \in(0,1), \tau \in(\lambda, 1)$. Intuitively, the test statistic $M$ in equation (5) is obtained as the minimum of the double-recursive sequence $\operatorname{DF}_{G}(\lambda, \tau), \lambda \in(0,1)$ and $\tau \in(\lambda, 1)$, and the break dates are obtained in the same way.

The literature on unit root testing agrees that unit root tests may be biased towards committing type II errors when there are structural breaks in the data generation process which are not taken into account in the auxiliary regression (see Perron 1989, among many others). Unlike the previous unit root tests with structural breaks, Lee and Stratizicich (2003) propose a test which incorporates breaks in both the null and the alternative hypothesis. This is an important novelty, since the authors find that previous unit root tests with breaks would not incorporate breaks under the null hypothesis. Another novelty is that they account for two breaks instead of one in the deterministic components. The dates of the breaks are endogenously determined and are selected by minimising the $t$-statistic associated with the autoregressive parameter, providing more evidence against the null hypothesis. It is important for this feature of the data generation processes to be taken into account for CEECs, as these countries have undergone profound reforms which may have affected the dynamics of debt (Cuestas and Staehr, 2013).

Finally, the Bai and Perron (2003) method allows not only for testing for the number of breaks in the parameters of an equation, a type of nonlinear model which implies that the parameters are segmented by date, but also for estimation of this type of nonlinear model. A typical broken equation in the sense of Bai and Perron (2003) for the case of reaction functions looks like 


$$
B_{t}=\gamma_{1} I\left(t<T_{b}\right)+\gamma_{2} I\left(t \geq T_{b}\right)+\alpha_{1} t I\left(t<T_{b}\right)+\alpha_{2} t I\left(t \geq T_{b}\right)+\beta_{1} I\left(t<T_{b}\right) B_{t-1}+\beta_{2} I\left(t \geq T_{b}\right) B_{t-1}+\varepsilon_{t}
$$

where I(.) is the indicator function, which takes the value 1 if the condition in parentheses is satisfied or 0 otherwise. In equation (6) we have assumed only one structural break, defining two temporal segments for the parameters. However, the number of breaks can be estimated with the Bayesian information criterion. Alternatively the Schwarz criterion modification as proposed by Liu et al. (1997) can be used. Bai and Perron (2003) also propose a sequential procedure based on an F-type test for the null of 0 breaks against the alternative of $k$ breaks or the null of $k-1$ breaks versus the alternative of $k$ breaks. In the next section we use all these methods to get a firmly grounded decision about the number of breaks.

In general the idea is that the way governments accumulate debt, proxied by the autoregressive parameter, may have changed over time. This parameter variation may be due to political conditions, euro area membership, times of financial distress, or other factors. The aim here is to account for those changes and analyse how the dynamics of the debt stock have changed over time.

\section{Empirical analysis}

\subsection{The data}

The data for this empirical analysis consist of quarterly observations of government debt stock as a percentage of GDP, ${ }^{1}$ obtained from Eurostat (code gov_q_ggdebt). Our group of CEECs consists of Bulgaria, Croatia, the Czech Republic, Estonia, Hungary, Latvia, Lithuania, Poland, Romania, Slovakia and Slovenia. The data span 2000Q1-2014Q1, except for Croatia where the

\footnotetext{
${ }^{1}$ It refers to the general government gross consolidated debt.
} 
series starts in 2001Q4. The data for Hungary, Lithuania and Slovenia, where the multiplicative X12 procedure indicated evidence of seasonality, have been seasonally adjusted.

The time series data plots appear in Figure 1. It is easy to observe how the debt ratios increased drastically after 2008 everywhere except Bulgaria as a consequence of the automatic stabilisers plus the discretionary expansionary fiscal policies that were passed to accommodate the drop in aggregate demand. The case of Estonia is also worth mentioning since the figure shows that there was a reduction between 2010 and 2012 in the debt-to-GDP ratio levels. This was caused by the tightening of fiscal policy in the preparation period for euro adoption.

\section{[Figure 1 about here]}

Figure 2 shows a circular chart that compares the different levels of debt. Bulgaria is the country with by far the best performance in debt reduction, particularly before 2008, while Hungary is probably the worst in terms of debt levels, especially after the crisis, when the debt hit levels of more than $80 \%$ of GDP. Hungary was one of the countries that needed IMF bailouts, together with Latvia and Romania. Again, it is worth mentioning the case of Estonia, which had the lowest level of debt to GDP even after the crisis.

\section{[Figure 2 about here]}

It is also shows how some of the countries improved their debt situation to prepare for EU admission and euro adoption, as for instance is shown by the last couple of years for Latvia and Lithuania.

\subsection{Results}

As preliminary analysis, we have applied the Ng and Perron (2001) unit root test for the whole period and for the period after the crisis ignited. These results are presented in the second and third columns of Table 1 . The test has been applied in a model with both trend and drift, and with 
the lag length obtained from the modified Akaike information criterion proposed by $\mathrm{Ng}$ and Perron (2001). According to the analysis for the full period, the unit root hypothesis is only rejected at conventional significance levels for Bulgaria, Lithuania and Slovenia, so there is evidence of mean reversion for these countries. However, when only the period from 2008Q1 onwards is considered, the unit root hypothesis cannot be rejected in any of the cases. That there is not a single case where the unit root can be rejected may be because of the low power or bias over non-rejecting the null in short samples. This justifies the use of the other tests which incorporate the possibility of breaks without losing observations.

The results of the Lee and Straticizich (2003) test with two breaks in the trend and the intercept and a maximum of eight lags are shown in column 4 of Table 1 . The unit root hypothesis can only not be rejected for the Czech Republic, Poland and Slovakia. In the remaining cases, the series of the debt-to-GDP ratio are stationary once breaks in the deterministic components are allowed. As expected, the first structural break is in most cases close to 2008 and the second is around 2010, which is when some of the countries were starting to prepare to fulfil the Maastricht Criteria and adopt the single common currency.

More interesting results are found by the Leybourne et al. (2007) test, since we are able to find from it the periods in which the series change their order of integration from I(1) to I(0) and from $\mathrm{I}(0)$ to $\mathrm{I}(1)$. The results are reported in the last column of Table 1 . Here we can distinguish two groups of countries. The first group consists of Bulgaria, Hungary, Lithuania and Poland, where the debt-to-GDP ratio appears to be stationary for some time just before or close to the start of the crisis. This shows the explicit behaviour of the debt stock as a percentage of the GDP in these countries. If we look at the plots in Figure 1, we can see how the debt-to-GDP ratio changes in trend and stabilises after 2008. For the remaining countries we observe how the debtto-GDP ratio behaves as a stationary process before the start of the crisis. This is something, 
again, that is quite clear from the plots. It is curious how the $\mathrm{I}(0)$ period for Latvia resembles that for Estonia.

\section{[Table 1 about here]}

The results from the last column of Table 1 should be complemented with a method where changes in the three types of parameters for drift, trend and slopes are allowed for, without the breaks having to be restricted to periods where the order of integration changes. The aim is to estimate equation (5), and the Bai and Perron (2003) method serves this purpose as mentioned earlier. First, we need to determine the number of breaks in the broken or segmented equation. In the third column of Table 2, we report the results of the Bayesian information criterion, the Liu et al. (1997) criterion results are in column 4, and the two F tests are reported in columns 5 and 6. The decision on the number of breaks is taken from a maximum of two (see Cuestas et al., 2014) and is a joint decision using all the statistics mentioned above. The result is that we find there are two breaks for Bulgaria, Latvia, Lithuania and Slovenia, but only one for the rest. This is arrived at purely using the statistical method.

\section{[Table 2 about here]}

In Table 3 we present the estimated parameters for equation (6). Interestingly, and as with the results obtained in Table 1 , one of the breaks coincides with the start of the crisis in most cases, with the exceptions of Bulgaria, Estonia and Poland. For Bulgaria we find increases in the autoregressive parameter in 2002 and 2004, the latter being quite close to the unit root. The case of Estonia is again peculiar as the break appears in 2012, well after the country joined the euro. The autoregressive parameter changes from a value close to the unit root to one quite close to zero after 2012. This is sensible if we look at the evolution of the Estonian debt-to-GDP ratio in Figure 1 from 2012. For Croatia, the Czech Republic, Hungary, Latvia, Slovakia and Slovenia we observe a reduction after the crisis in the speed of mean reversion, meaning a 
reduction in the autoregressive parameter. Finally, for Lithuania and Romania we find that the autoregressive parameter increases significantly after the start of the crisis. However, the change in the estimated coefficient for the trend also deserves attention. We need to highlight the cases of Croatia and the drastic change for Slovenia. The latter should be a source of concern as Slovenia is reaching significant levels of debt stock over GDP, and the trend seems to indicate a substantial future accumulation of debt.

\section{[Table 3 about here]}

\section{Conclusion}

The analysis of sovereign debt sustainability has gathered momentum in the academic literature as the collapse of the global economy after 2008 obliged many governments to reconsider their fiscal policies to avoid defaults.

This paper has analysed how the debt-to-GDP ratio dynamics have changed over time for a group of CEECs. The analysis is related to the testing of fiscal sustainability, in that it looks at how fiscal authorities accumulate debt over time. However, given that the way governments accumulate debt may have been subject to structural changes, we introduce the novelty of analysing the way that past debt stock feeds into present debt stock has changed over time, using a battery of methods. The statistical approach relies in consequence upon analysing what happens over time with the autoregressive parameter. This is directly linked with unit root testing and the estimation of segmented equations. However, it should be borne in mind that different theoretical approaches to the issue of the sustainability of debt may need more complex econometric methods. Hence our results rely on a very particular econometric specification of the economic problem. 
From our analysis we can distinguish two groups of countries, which are those where the debt stock over GDP stabilises after the 2008 crisis and those where the sustainability of debt may be at risk after the crisis, with the cases of Croatia, Lithuania, Romania and Slovenia deserving a close look from the fiscal authorities. The cases of Croatia and Romania seem to highlight that more structural changes are necessary to stabilise their public finances in view of their potential membership of the euro area.

\section{References}

Bai, J., Perron, P. 2003. Computation and analysis of multiple structural change models. Journal of Applied Econometrics 18, 1-22.

Bohn, H., 2007. Are stationarity and cointegration restrictions really necessary for the intertemporal budget constraint? Journal of Monetary Economics 54, 1837-1847.

Bökemeier, B., Stoian, A., 2018. Debt Sustainability Issues in Central and East European Countries, Eastern European Economics, 56, 438-470.

Chortareas, G., Kapetanios, G., Uctum, M., 2008. Nonlinear Alternatives to Unit Root Tests and Public Finances Sustainability: Some Evidence from Latin American and Caribbean Countries. Oxford Bulletin of Economics and Statistics 70, 645-663.

Cuestas, J.C., 2013. The current account sustainability of European transition economies. Journal of Common Market Studies 51, 232-245. 
Cuestas, J.C., Staehr, K., 2013. Fiscal shocks and budget balance persistence in the EU countries from Central and Eastern Europe. Applied Economics 45, 3211-3219.

Cuestas, J.C., Gil-Alana, L.A., Staehr, K., 2014. Government debt dynamics and the global financial crisis: Has anything changed in the EA12? Economics Letters 124, 64-66.

Cunado, J., Gil-Alana, L.A., Perez de Gracia, F., 2004. Is the US fiscal deficit sustainable? A fractionally integrated approach. Journal of Economics and Business 56, 501-526.

Cunado, J., Gil-Alana, L.A., Perez de Gracia, F., 2010. European current account sustainability: New evidence based on unit roots and fractional integration. Eastern Economic Journal 36, 177187.

De Grauwe, P., 2012. Governance of a fragile Eurozone. Australian Economic Review 45, 25268.

Gros, D., 2012. On the stability of public debt in a monetary union. Journal of Common Market Studies 50, 36-48.

Holmes, M., Panagiotidis, T., Sharma, A., 2011. The sustainability of India’s current account. Applied Economics 43, 219-229.

Krajewski, P., Mackiewicz, M., Szymańska, A., 2016. Fiscal Sustainability in Central and Eastern European Countries - A Post-Crisis Assessment. Prague Economic Papers 25,175-88. 
Lee, J.,Strazicich, M. C., 2003. Minimum LM unit root test with two structural breaks, Review of Economics and Statistics 85, 1082-1089.

Legrenzi, G.D., Milas, C., 2012. Debt sustainability and financial crises: Evidence from the GIIPS. Economics Bulletin 32, 2586-2593.

Leybourne, S., Kim, T.-H.,Taylor, A. M. R., 2007. Detecting multiple changes in persistence, Studies in Nonlinear Dynamics and Econometrics 11, 1-34.

Liu J.,Wu, S., Zidek, J. V., 1997. On segmented multivariate regressions. Statistica Sinica 7, 497-525.

Ng, S. and Perron, P., 2001. Lag selection and the construction of unit root tests with good size and power. Econometrica 69, 1519-1554

Perron, P., 1989. The great crash, the oil price shock and the unit root hypothesis. Econometrica 57, 1361-1401. 
Table 1: Unit root tests results

\begin{tabular}{lcccc}
\hline Country & Ng-Perron & $\begin{array}{c}\text { Ng-Perron, } \\
\text { crisis sample }^{\mathrm{a}}\end{array}$ & $\begin{array}{c}\text { LS structural } \\
\text { breaks for I(0) }\end{array}$ & $\begin{array}{c}\text { LKT interval with } \\
\text { I(0) }\end{array}$ \\
\hline Bulgaria & $\mathrm{I}(0)$ & $\mathrm{I}(1)$ & 2006:Q4 2008Q2 & 2006Q2- 2010Q4 \\
\hline Croatia & $\mathrm{I}(1)$ & $\mathrm{I}(1)$ & 2007Q3 2010Q1 & 2002Q4-2007Q2 \\
\hline Czech Rep. & $\mathrm{I}(1)$ & $\mathrm{I}(1)$ & $\mathrm{I}(1)$ & 2004Q4-2009Q2 \\
\hline Estonia & $\mathrm{I}(1)$ & $\mathrm{I}(1)$ & 2003Q2 2006Q4 & 2000Q4-2005Q2 \\
\hline Hungary & $\mathrm{I}(1)$ & $\mathrm{I}(1)$ & 2009Q1 2011Q3 & 2008Q1-2012Q3 \\
\hline Latvia & $\mathrm{I}(0)$ & $\mathrm{I}(1)$ & 2006Q4 2010Q3 & 2001Q1-20054Q3 \\
\hline Lithuania & $\mathrm{I}(1)$ & $\mathrm{I}(1)$ & 2007Q3 2010Q3 & 2006Q3-2011Q1 \\
\hline Poland & $\mathrm{I}(1)$ & $\mathrm{I}(1)$ & $\mathrm{I}(1)$ & 2008Q3-2013Q1 \\
\hline Romania & $\mathrm{I}(1)$ & $\mathrm{I}(1)$ & 2008Q4 2009Q3 & 2000Q1-2004Q3 \\
\hline Slovakia & $\mathrm{I}(1)$ & $\mathrm{I}(1)$ & $\mathrm{I}(1)$ & 2003Q1-2007Q3 \\
\hline Slovenia & $\mathrm{I}(0)$ & $\mathrm{I}(1)$ & 2006Q4 2009Q3 & 2003Q1-2007Q3 \\
\hline
\end{tabular}

a The crisis sample comprises the period 2008:1-2014:4.

Note: I(0) at the $10 \%$ significance level at least. 
Table 2: Bai and Perron (2003) determination of breaks

\begin{tabular}{|c|c|c|c|c|c|c|}
\hline & Breaks (k) & BIC & LWZ & $F(k \mid 0)$ & $\mathrm{F}(k \mid k-1)$ & Decision \\
\hline \multirow{3}{*}{ Bulgaria } & 0 & 1.42 & 1.56 & - & - & \multirow{3}{*}{2} \\
\hline & 1 & 0.83 & $1.11 \dagger$ & $20.56^{* *}$ & $20.56^{* *}$ & \\
\hline & 2 & $0.69 \dagger$ & 1.12 & $17.12^{* *}$ & 6.68 & \\
\hline \multirow{3}{*}{ Croatia } & 0 & 1.07 & 1.22 & - & - & \multirow{3}{*}{1} \\
\hline & 1 & 0.59 & $0.88 \dagger$ & $15.17^{*}$ & $15.17 *$ & \\
\hline & 2 & $0.59 \dagger$ & 1.03 & 10.75 & 3.59 & \\
\hline \multirow{3}{*}{ Czech Republic } & 0 & 0.36 & 0.50 & - & - & \multirow{3}{*}{1} \\
\hline & 1 & 0.20 & $0.48 \dagger$ & 7.59 & 7.59 & \\
\hline & 2 & $0.07 \dagger$ & 0.50 & 8.21 & 6.38 & \\
\hline \multirow{3}{*}{ Estonia } & 0 & -1.56 & -1.42 & - & - & \multirow{3}{*}{1} \\
\hline & 1 & -1.92 & $-1.64 \dagger$ & 13.05 & 13.05 & \\
\hline & 2 & $-1.97 \dagger$ & -1.54 & 10.31 & 4.69 & \\
\hline \multirow{3}{*}{ Hungary } & 0 & 1.80 & 1.93 & - & - & \multirow{3}{*}{1} \\
\hline & 1 & 1.44 & $1.72 \dagger$ & 12.75 & 12.75 & \\
\hline & 2 & $1.31 \dagger$ & 1.73 & 11.75 & 6.52 & \\
\hline \multirow{3}{*}{ Latvia } & 0 & 1.67 & 1.80 & - & - & \multirow{3}{*}{2} \\
\hline & 1 & 0.98 & 1.26 & $24.25 * *$ & $24.25 * *$ & \\
\hline & 2 & $0.27 \dagger$ & $0.70 \dagger$ & $40.68^{* *}$ & $23.86^{* *}$ & \\
\hline \multirow{3}{*}{ Lithuania } & 0 & 0.85 & 0.99 & - & - & \multirow{3}{*}{2} \\
\hline & 1 & 0.07 & 0.35 & $28.47^{* *}$ & $28.47 * *$ & \\
\hline & 2 & $-0.10 \dagger$ & $0.33 \dagger$ & $23.34^{* *}$ & 7.35 & \\
\hline \multirow{3}{*}{ Poland } & 0 & 1.20 & 1.34 & - & - & \multirow{3}{*}{1} \\
\hline & 1 & $0.89 \dagger$ & $1.17 \dagger$ & 11.48 & 11.48 & \\
\hline & 2 & 0.90 & 1.32 & 8.50 & 3.68 & \\
\hline \multirow{3}{*}{ Romania } & 0 & 0.79 & 0.93 & - & - & \multirow{3}{*}{1} \\
\hline & 1 & $0.43 \dagger$ & $0.71 \dagger$ & 13.19 & 13.19 & \\
\hline & 2 & 0.47 & 0.89 & 8.81 & 2.92 & \\
\hline \multirow{3}{*}{ Slovakia } & 0 & 1.28 & 1.41 & - & - & \multirow{3}{*}{1} \\
\hline & 1 & $0.90 \dagger$ & $1.18 \dagger$ & 13.35 & 13.35 & \\
\hline & 2 & 0.96 & 1.39 & 8.65 & 2.63 & \\
\hline \multirow{3}{*}{ Slovenia } & 0 & 1.36 & 1.50 & - & - & \multirow{3}{*}{2} \\
\hline & 1 & 1.30 & 1.58 & 5.32 & 5.32 & \\
\hline & 2 & $0.71 \dagger$ & $1.14 \dagger$ & $15.24^{*}$ & $19.31 * *$ & \\
\hline
\end{tabular}

Note: The minimum value for each of the Bayesian Information Criteria (BIC) and Lee et al. (2003) tests (LWZ) is shown with $\dagger$. Superscript $* *$ denotes rejection of the null at the $5 \%$ significance level, whereas * means rejection of the null at the $10 \%$ level. 
Table 3: Estimation of the broken equations

\begin{tabular}{|c|c|c|c|c|c|}
\hline & $\begin{array}{l}\gamma_{1} \\
\beta_{1} \\
\alpha_{1}\end{array}$ & $T_{1}$ & $\begin{array}{l}\gamma_{2} \\
\boldsymbol{\beta}_{2} \\
\boldsymbol{\alpha}_{2}\end{array}$ & $T_{2}$ & $\begin{array}{l}\gamma_{3} \\
\boldsymbol{\beta}_{3} \\
\boldsymbol{\alpha}_{3}\end{array}$ \\
\hline & 117.08 & & 57.66 & & -0.96 \\
\hline \multirow{3}{*}{ Bulgaria } & -0.41 & 2002Q1 & 0.20 & 2004Q2 & 0.91 \\
\hline & -2.85 & & -1.33 & & 0.05 \\
\hline & 2.20 & & -18.42 & & \\
\hline \multirow[t]{3}{*}{ Croatia } & 0.96 & 2007Q4 & 0.45 & - & - \\
\hline & -0.05 & & 0.98 & & \\
\hline & 2.84 & & 5.09 & & \\
\hline \multirow[t]{3}{*}{ Czech Republic } & 0.91 & 2009Q1 & 0.64 & - & - \\
\hline & -0.01 & & 0.20 & & \\
\hline & 0.13 & & 6.01 & & \\
\hline \multirow[t]{3}{*}{ Estonia } & 0.94 & 2012Q2 & 0.11 & - & - \\
\hline & 0.00 & & 0.05 & & \\
\hline & 13.75 & & 54.54 & & \\
\hline \multirow[t]{3}{*}{ Hungary } & 0.73 & 2008Q3 & 0.32 & - & - \\
\hline & 0.14 & & 0.01 & & \\
\hline & 1.74 & & -49.98 & & 28.46 \\
\hline \multirow[t]{3}{*}{ Latvia } & 0.88 & 2008Q3 & 0.03 & 2009Q2 & 0.58 \\
\hline & -0.01 & & 1.92 & & -0.22 \\
\hline & 17.52 & & -76.54 & & 12.49 \\
\hline \multirow[t]{3}{*}{ Lithuania } & 0.32 & 2008Q3 & 0.45 & 2010Q1 & 0.66 \\
\hline & -0.21 & & 2.36 & & 0.01 \\
\hline & 4.83 & & -554.84 & & \\
\hline \multirow[t]{3}{*}{ Poland } & 0.87 & 2013Q2 & 9.57 & - & - \\
\hline & 0.04 & & 1.01 & & \\
\hline & 6.03 & & 4.27 & & \\
\hline \multirow[t]{3}{*}{ Romania } & 0.78 & 2008Q3 & 0.90 & - & - \\
\hline & -0.11 & & -0.00 & & \\
\hline & 25.50 & & -14.70 & & \\
\hline \multirow[t]{3}{*}{ Slovakia } & 0.53 & 2007Q4 & 0.38 & - & - \\
\hline & -0.39 & & 0.91 & & \\
\hline & 7.16 & & -17.89 & & -382.71 \\
\hline \multirow[t]{2}{*}{ Slovenia } & 0.75 & 2009Q1 & 0.15 & 2013Q1 & -0.63 \\
\hline & -0.03 & & 1.20 & & 8.85 \\
\hline
\end{tabular}

Note: $T_{1}$ indicates the month of the first time break, $T_{2}$ indicates the month of the second time break. 


\section{Figure 1: Time series data plots}
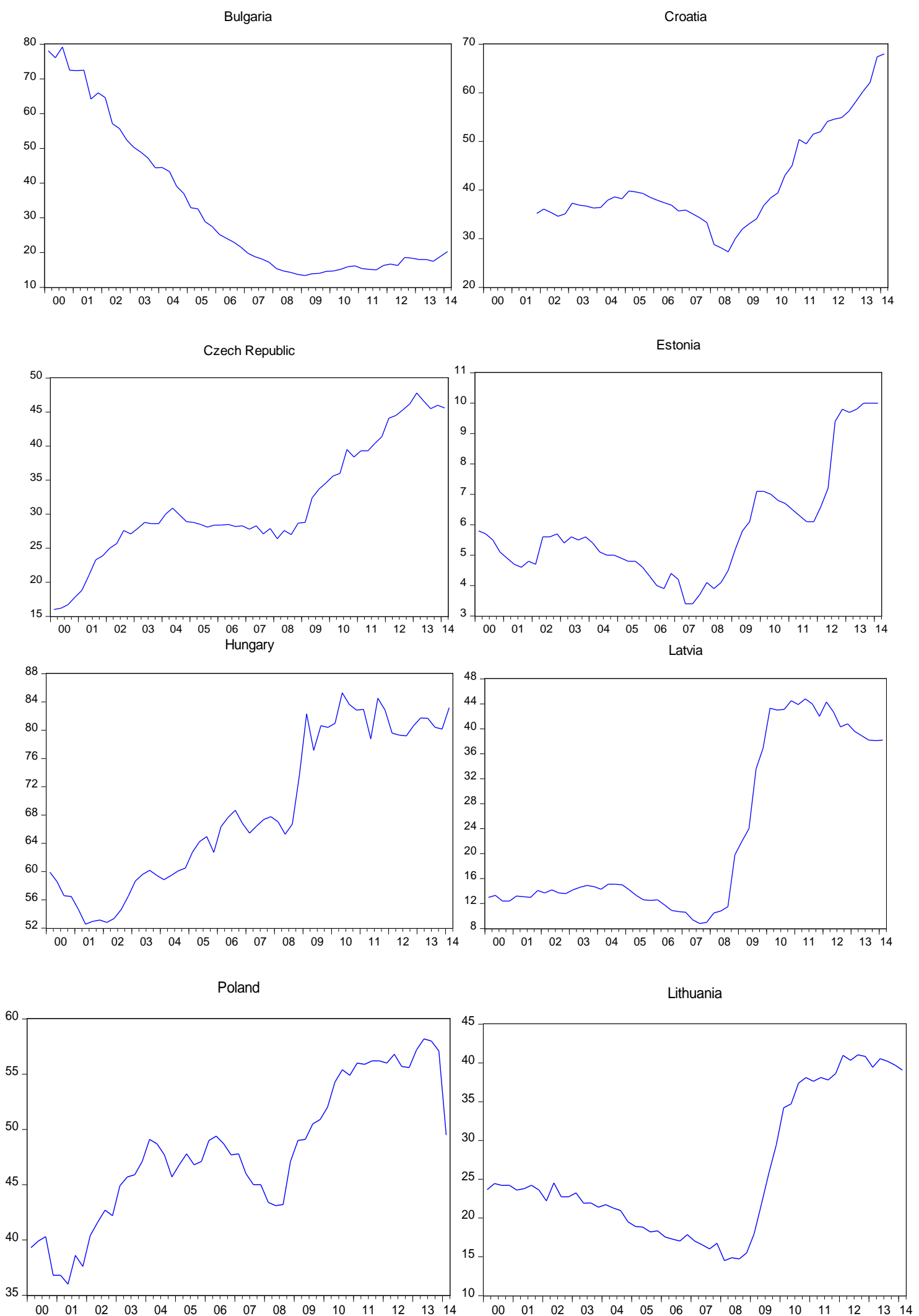

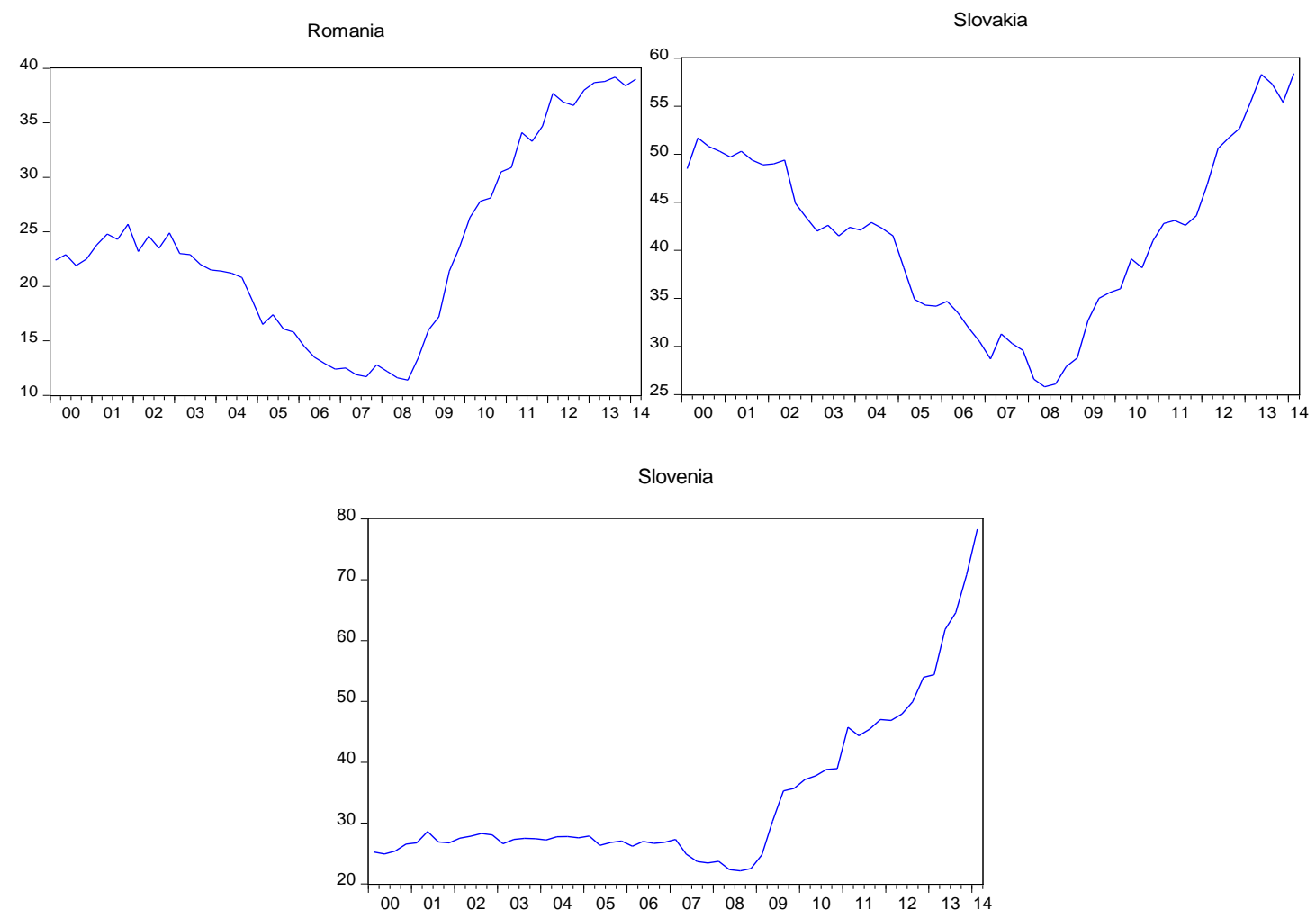

Source: Eurostat 
Figure 2: Chart comparing debt stock/GDP \%

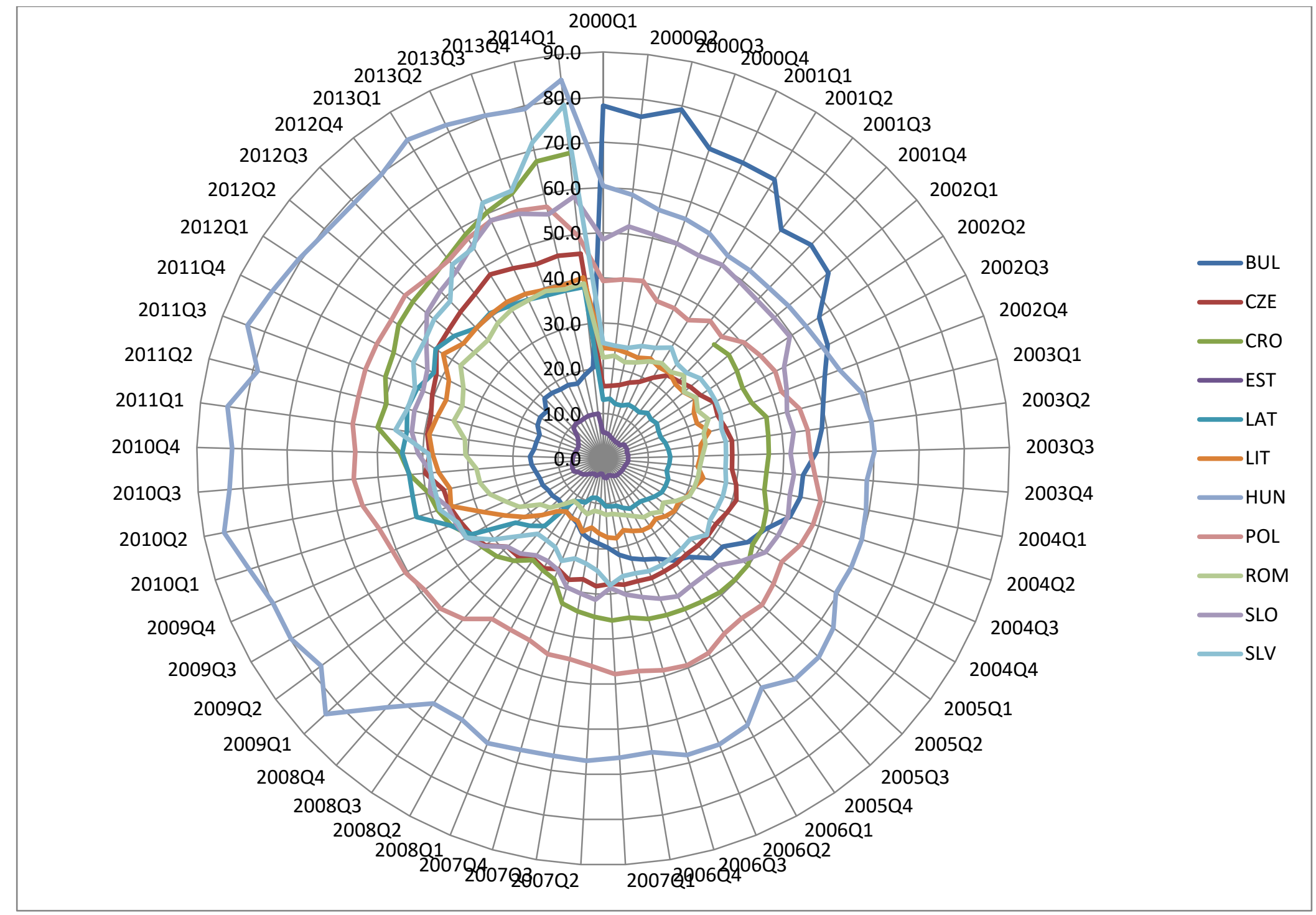

Source: Eurostat 
